\title{
O PROCESSO HISTÓRICO DE (RE)CONHECIMENTO DA IDENTIDADE DOS POMERANOS COMO POVO TRADICIONAL NO BRASIL
}

\author{
André Filipe Pereira Reid dos Santos ${ }^{1}$ \\ Rosaly Stange Azevedo
}

\begin{abstract}
Resumo
O presente artigo tem por objetivo elucidar alguns aspectos relevantes para se compreender a situação de isolamento dos grupos pomeranos, importante fator na manutenção da identidade desse grupo étnico incluído como povo tradicional no Brasil. Busca-se reconstruir a trajetória histórica desses grupos, de forma a possibilitar a identificação da luta envolvendo grupos com interesses antagônicos no processo de (re)conhecimento da identidade da comunidade pomerana. O método de investigação utilizado é o dialético, mediante à contraposição de ideias conflitantes. A base teórica principal do trabalho transita entre textos de tradição marxista.
\end{abstract}

Palavras-chave: Identidade. Processo histórico. Pomeranos. Povos tradicionais.

\section{INTRODUÇÃO}

O processo de (re)conhecimento da identidade dos grupos pomeranos configura uma diversidade de tempos históricos contraditórios, que passaram por momentos de desejo e de aceitação, no início da imigração; de

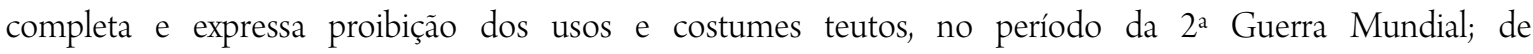
desconhecimento dos grupos e de sua forma de vida, até chegar ao reconhecimento formal, pela sua inserção como povo tradicional. O objetivo do presente artigo é abordar alguns aspectos desse processo como forma de se compreender a situação de isolamento, importante fator na manutenção da identidade desse grupo étnico.

A dificuldade teórica de avançar uma hipótese construtiva na análise do processo de reconhecimento e inclusão dos pomeranos como povo tradicional demanda a observância de três passos subsequentes, que serão articulados neste artigo: 1) analisar alguns aspectos ligados à identidade dos pomeranos que os fizeram manter costumes seculares; 2) reconstruir, de forma resumida, parte da trajetória histórica desses grupos, por meios da narrativa de descendentes de pomeranos, durante a pesquisa de campo no Município de Santa Maria de Jetibá, no

\footnotetext{
${ }^{1}$ Doutor em Ciências Humanas pelo Programa de Pós-graduação em Sociologia e Antropologia da Universidade Federal do Rio de Janeiro (UFRJ). Professor/pesquisador do Programa de Pós-graduação Stricto Sensu em Direitos e Garantias Fundamentais da Faculdade de Direito de Vitória (FDV).E-mail: afprsantos@gmail.com

${ }^{2}$ Mestranda em Direito pela Faculdade de Direito de Vitória. Gestora Regional do Programa de Erradicação do Trabalho Infantil do Tribunal Superior do Trabalho. E-mail: rosalystange@terra.com.br
} 
Estado do Espírito Santo, apresentando fotografias tiradas durante a elaboração da pesquisa; e, 3 ) identificar a luta envolvendo grupos com interesses antagônicos no processo de (re)conhecimento da identidade da comunidade pomerana.

Optou-se por utilizar o método de investigação dialético, mediante à contraposição de ideias conflitantes, compreendendo a análise desses elementos em um fenômeno, que, no caso deste trabalho, serão as lutas pelo lugar do grupo pomerano camponês. A base teórica principal do trabalho transita entre textos de tradição marxista, seguindo a tradição da análise chayanoviana, ao considerar o campesinato uma modalidade de trabalho na qual o trabalhador da unidade agrária familiar camponesa define, ele mesmo, a intensidade de seu trabalho, a quantidade de horas trabalhadas, a medida de retorno de seu esforço, em uma auto-sujeição a que Chayanov chama de regime de autoexploração. Este aspecto tem relevância, pois uma das principais características do grupo em estudo é o trabalho coletivo em bases familiares.

O fator capaz de fundamentar a resistência dos pomeranos em se integrarem na ordem social pode ser resumido por um termo: Deutschtum, palavra que tem por tradução a noção de germanidade, algo como, para o brasileiro, a brasilidade. Este sentimento subjetivo estabelece ser o direito de sangue o fator determinante para a nacionalidade, acima do Estado, das regras de cidadania e do nascimento (SEYFERTH, 1981, p. 18). O Deutschtum participa fortemente da "subjetividade socializada" (Bourdieu, 1992, p. 108, apud SETTON, 2002, p. 64, nota de rodapé), que integra as experiências passadas dos imigrantes alemães e funciona como um leque de percepções e atitudes, em esquemas valorativos inconscientes, introjetados, naquilo que Bourdieu (1989, p. 65) chama de habitus.

A força teórica do Deutschtum sobre a formação do habitus do camponês pomerano tem correspondência com duas posições antagônicas que marcam a história da Alemanha, diretamente ligadas ao processo de unificação do Estado Nacional alemão. Em um polo encontra-se o esforço pela unificação política e, em outro, a busca pelo reconhecimento das particularidades de cada Estado. Os primeiros nacionalistas que chegaram a idealizar uma "nação alemã" vieram do movimento romântico. O filósofo J. G. Herder desenvolve a noção de Volksgeist (alma ou espírito do povo), conceito que, simultaneamente, nega o universal e valoriza as particularidades de um povo. Herder compreende os homens como membros de comunidades nacionais e não de Estados, estes últimos, criações artificiais, enquanto que a nacionalidade seria uma criação divina: "As implicações políticas da nacionalidade ficam em segundo plano". O que está implícito na obra de Herder é o respeito à liberdade nacional e às linguagens nacionais: os alemães devem ser um povo livre sobre um solo que lhes pertence. O ideário do nacionalismo alemão adveio dos conflitos entre França e Alemanha, incluindo o período de dominação napoleônica (SEYFERTH, 1981, pp. 19-20). O ideal cultivado pelos alemães é mais de uma nação do que de um Estado Nacional. 
Em qualquer grupo teuto-brasileiro, o tema da identidade étnica possui intensa conexão com a ideia da germanidade, ou germanismo - Deutschtum, ideologia étnica divulgada nas colônias alemãs pela imprensa alemã desde 1852 e também pela influência dos pastores protestantes enviados pela Alemanha ao Brasil, pressupõe uma classificação dos indivíduos mediante categorias referidas pela concepção de origem comum, herança cultural e ancestralidade. Encontra-se, subjacente ao Deutschtum, uma ideia de solidariedade e de igualdade entre os indivíduos que partilham uma mesma identidade étnica, uma espécie de "patrimônio cultural alemão" (SEYFERTH, p. 83).

O caminho trilhado pelos camponeses teutos, em sua saga no Brasil, teve seu ponto de partida na percepção da natureza dispensável da estrutura de poder. Uma existência marcada por fases que vão do "imigrante desejado" para o "indesejado", desconhecido e, finalmente, protegido. Os distintos períodos serão abordados a seguir.

\section{A OCUPAÇÃO DO TERRITÓRIO: A CHEGADA DO “IMIGRANTE DESEJADO”}

Desde suas raízes, o campesinato brasileiro se mistura com processos históricos que extrapolam nossas fronteiras em razão da colonização europeia: "momento em que as tradicionais formas de gestão do território, com toda a sua pluralidade, sofrem violento assalto, sendo sistematicamente banidas em favor de um controle exógeno e centralizado" (PAULINO, 2012, p. 75). Assim, a chegada do imigrante alemão ao Brasil guarda profunda interconexão com o modo como ocorreu a apropriação do território e a distribuição das terras brasileiras.

A primeira, e precipitada, impressão que se tem é de que a distribuição desigual de terras no Brasil foi um processo fundado no acaso, sem qualquer planejamento ou intenção política. Um olhar mais atento, entretanto, permite perceber que tal assertiva é, em verdade, equivocada. Toda a legislação fundiária, desde o período das sesmarias, passando pela Lei de Terras, teve por principal objetivo criar um monopólio de classe sobre a terra em todas as regiões do país, incluindo aquelas não ocupadas economicamente, de forma a interditar o acesso do trabalhador comum à terra, obrigando-o a trabalhar para o capital, diante da impossibilidade de trabalhar para si e sua família (MARTINS, 2013, p. 124). Todas as formas de apropriação do território favoreceram, e ainda favorecem, a concentração da propriedade privada da terra, marcada por excessiva valorização, com o objetivo de cercear o acesso a ela, mediante a lógica do desequilíbrio da oferta e da procura. A extração do excedente social do campo depende, portanto, de tal configuração desigual.

A concentração fundiária tem por consequência nefasta o aumento da oferta da mão de obra em proporção superior à capacidade de aproveitamento no campo, forçando a procura de empregos em área urbana. Além do alto valor da terra e dos poucos postos de trabalho ofertados em razão da mecanização das atividades, o 
homem do campo encontra grandes dificuldades de concluir seus estudos, fator de intensificação da precarização e da exclusão do trabalhador do campo. A característica nuclear da estrutura fundiária brasileira ${ }^{3}$ é precisamente o alto grau de concentração. A situação de interdição ao acesso à terra percorre a história de todos os povos que se encontram ou se encontraram em posição de resistência no processo secular de exclusão: índios, negros e caboclos, como salientado por Paulino (2012, p. 38).

A política de distribuição de terras, no período do Brasil-Colônia, coincidia, em seus aspectos principais, com a teoria de Wakefield sobre a "colonização sistemática", que se fundamentava na noção de que as terras não ocupadas não deviam ser entregues ao homem pobre por preços baixos, ainda que a terra fosse acessível, para evitar que os trabalhadores mais competentes se transformassem em pequenos proprietários e não aceitassem vender sua força de trabalho às grandes propriedades. Deveria ser, portanto, fixado um valor "suficientemente alto", de forma a se obstar que os pobres do campo se tornassem independentes (GUIMARÃES, 2009, p. 49). Enquanto vigorava o sistema de sesmarias, não era necessário recorrer a essas fórmulas de elevação dos preços das propriedades, pois a terra não era uma mercadoria: era ainda um privilégio de um pequeno grupo. Assim, impedir que o homem pobre tivesse acesso à terra era simples: bastava impedir as ocupações por meios violentos e as doações por institutos jurídicos.

A política imigratória que vigorou na passagem do século XIX e no início da década de 1930 dividiu os imigrantes, em geral, em dois grupos: os que eram encaminhados para núcleos coloniais oficiais na condição de pequenos proprietários, e os que eram encaminhados para a Hospedaria dos Imigrantes em São Paulo, onde permaneciam de três a oito dias e, em seguida, eram enviados de trem para as fazendas do interior. Segundo Martins (2013, p. 102), "De 1851 a 1909 o governo imperial promoveu a imigração subvencionada. A partir de 1881 o governo de São Paulo, movido pelos interesses dos fazendeiros do café, também aplicou grandes recursos na imigração estrangeira até 1927, pouco antes da Grande Crise de 1929”. Ambos os grupos tinham limitada a sua liberdade de se deslocar no território nacional e de decidir para quem e onde trabalhar.

Os alemães constituíram o primeiro fluxo de imigrantes para o Brasil em 1808, na primeira fase da política imigratória, em que a imigração era subvencionada pelo poder público. Os contingentes mais significativos de imigrantes dessa nacionalidade datam de 1824. Contudo, o número de imigrantes alemães não foi significante em termos quantitativos na primeira metade do século XIX (SEYFERTH, 2000, p. 274-275).

A partir de 1840, a segunda fase do processo de colonização teve início, sob a iniciativa das "companhias particulares de colonização", mecanismo político escolhido como forma de diminuir as despesas estatais com a instalação das colônias. Essa mudança estratégica possui interconexão tanto com a promulgação da Lei nº. 581, de 04 de setembro de 1850 (Lei Euzébio de Queiroz), que proibiu o tráfico de escravos, quanto com a Lei nº. 601, de

\footnotetext{
${ }^{3} \mathrm{O}$ processo histórico de estabelecimento das políticas fundiárias no Brasil será mais detalhado no capítulo 2 deste estudo.
} 
18 de setembro do mesmo ano, a Lei de Terras (SEYFERTH, 2000, p. 279-280).

$\mathrm{Na}$ segunda metade do século XIX, houve regularidade na entrada de imigrantes alemães, principalmente direcionados para a região Sul, reduzindo, significativamente, na década de 1930. Nos anos que precederam e sucederam a Primeira Guerra Mundial o fluxo migratório foi mais intenso. Nos períodos entre 1909 a 1913 e 1919 a 1925, ingressaram nas fronteiras brasileiras, aproximadamente, um terço do total, desde 1808 (SEYFERTH, 2000, p. 274-275).

$\mathrm{Na}$ "imigração desejada", o imigrante ideal era o "homem do campo". Os europeus eram apreciados como "bons colonos", havendo uma hierarquização entre as nacionalidades europeias, privilegiando, inicialmente, alemães e suíços e, logo em seguida, os italianos e espanhóis (SEYFERTH, p. 280). Segundo Abrantes (1846, p.2), embaixador extraordinário em Berlim em 1845, o imigrante alemão possuía os requisitos necessários para o trabalho nas lavouras: "[...] o seu espírito pacífico e conservador acha-se provados por testemunhos os mais authenticos $[\ldots]$ moralidade $[\ldots]$ amor ao trabalho e à família, sobriedade, resignação, respeito às Authoridades, são as qualidades que distinguem os colonos alemaens, em geral, dos colonos de outras origens".

Ressalta-se que o enaltecimento da aptidão ao trabalho dos imigrantes europeus era uma qualidade altamente valorizada, resposta "mágica" para os problemas do atraso da civilidade e da formação étnica do país, pelo clareamento de sua gente, ao passo que o brasileiro nativo era descrito pela literatura da época como preguiçoso e avesso ao trabalho: "Encontrá-lo-eis sentado à porta do lar, fumando o seu cigarro de fumo mineiro, e olhando o seu cavalo, que rumina tão preguiçoso como ele [ ... Esta gente, mais guerreira que agricultora, não trabalha, lida, e a sua actividade não produz, consume-se" (ZALUAR, 1860, p. 103).

No contexto de alta mobilidade de grupos excluídos da participação mais ampla na sociedade, marginalizados nas fronteiras do mundo "civilizado", nasceu a imagem do "preguiçoso caipira". A baixa produtividade, restringida ao estritamente necessário para garantir a sobrevivência, à manutenção de padrões vitais mínimos, foi acentuada pela precarização das relações de trabalho. Esses grupos sempre viveram às margens das grandes propriedades agrícolas, revezando períodos de trabalho e períodos de ócio. A integração desses indivíduos varia de uma ligação permanente a uma completa ausência de relações, em um "mundo que lhes era paralelo, mas não de todo estranho" (FRANCO, 1997, p. 35).

Grupos de imigrantes alemães foram introduzidos na Província do Rio Grande do Sul em 1824 como soldados, integrando o Corpo de Estrangeiros, formado um ano antes no Rio de Janeiro, visando, principalmente, à proteção da região de fronteira, frequentemente em conflito fundiário com a população platina. O objetivo principal da política colonizadora do Império era garantir, militarmente, a independência em áreas contestadas (BIEHL, 1999, p. 149).

A condição de trabalhadores semiescravos nas lavouras de café, em substituição à mão-de-obra escrava, 
em razão das pressões inglesas ao tráfico de escravos, não foi aceita pelos imigrantes alemães. Os latifundiários não sabiam como se relacionar com o trabalhador livre europeu e acabavam por criar conflitos e insatisfações. Essa situação somente foi resolvida com a chegada dos imigrantes italianos em 1870, pois, com a abolição da escravatura, os grandes fazendeiros se viram obrigados a ceder pequenas melhorias aos novos trabalhadores, situação diversa da vivida pelos pioneiros imigrantes alemães (DREHER, 1984, p. 52).

A política imigratória do Império passou a direcionar os imigrantes para a criação de colônias, retornando à política de povoamento praticada por Dom João VI em seu curto período no Brasil. O imperador interessava-se pessoalmente, pelo tema do povoamento por brancos não portugueses, contrariando os interesses imediatistas dos grandes proprietários de terras, preocupados em manter os privilégios das elites e em evitar a divisão dos escassos recursos do Estado (IOTTI, 2003, p. 04). Após a independência, os soldados portugueses retornaram a Portugal e D. Pedro I passou a interessar-se pela contratação de mercenários alemães e, objetivando disfarçar a intenção militarista, passou a contratar também colonos com o objetivo de povoamento das terras do sul.

O plano consistia em atrair os imigrantes por intermédio de propagandas promovidas por agentes de imigração enviados para a Europa, inicialmente para os estados alemães e para a Suíça. As promessas eram, em grande parte, falsas, segundo Dreher (1984, p. 19) e, inclusive, feriam a constituição brasileira. A maioria dos imigrantes vinha para o Brasil para não mais retornar, pois tinham ciência das dificuldades que enfrentariam na viagem, tanto em relação aos valores que seriam despendidos, quanto no tocante as precárias condições de saúde e higiene.

Além disso, as condições de vida na Alemanha eram extremamente precárias e um eventual retorno não significaria uma melhoria. O que os motivava era a possibilidade de "fazer a América", uma nova vida, assumindo a cidadania brasileira (SEYFERTH, 1994, p. 31). Segundo Dreher (1995, p. 71), havia uma preocupação com a desproporção entre a população branca, que representava apenas $23 \%$ do total, e a população de negros - escravos ou libertos -, mestiços e indígenas. O medo era da ocorrência de revoltas "negras", como as que ocorreram no Haiti.

A valorização das terras e a criação das colônias são temas interconexos. Diante do fracasso atribuído à incompetência do governo imperial no estabelecimento de núcleos coloniais na Bahia, foi transferida, para a iniciativa privada, a atribuição de trazer imigrantes e estabelecê-los no território. Com o advento da Lei de Terras, de 18 de setembro de 1850, surgiu a possibilidade de grandes lucros com a atração de imigrantes pobres de seus países de origem. A terra era adquirida a preços baixíssimos do Estado ou de particular e, posteriormente, vendida aos imigrantes, em parcelas, como demonstram os documentos de venda de terras (figuras 1 e 2). 
Figura 1: Título de propriedade de terras

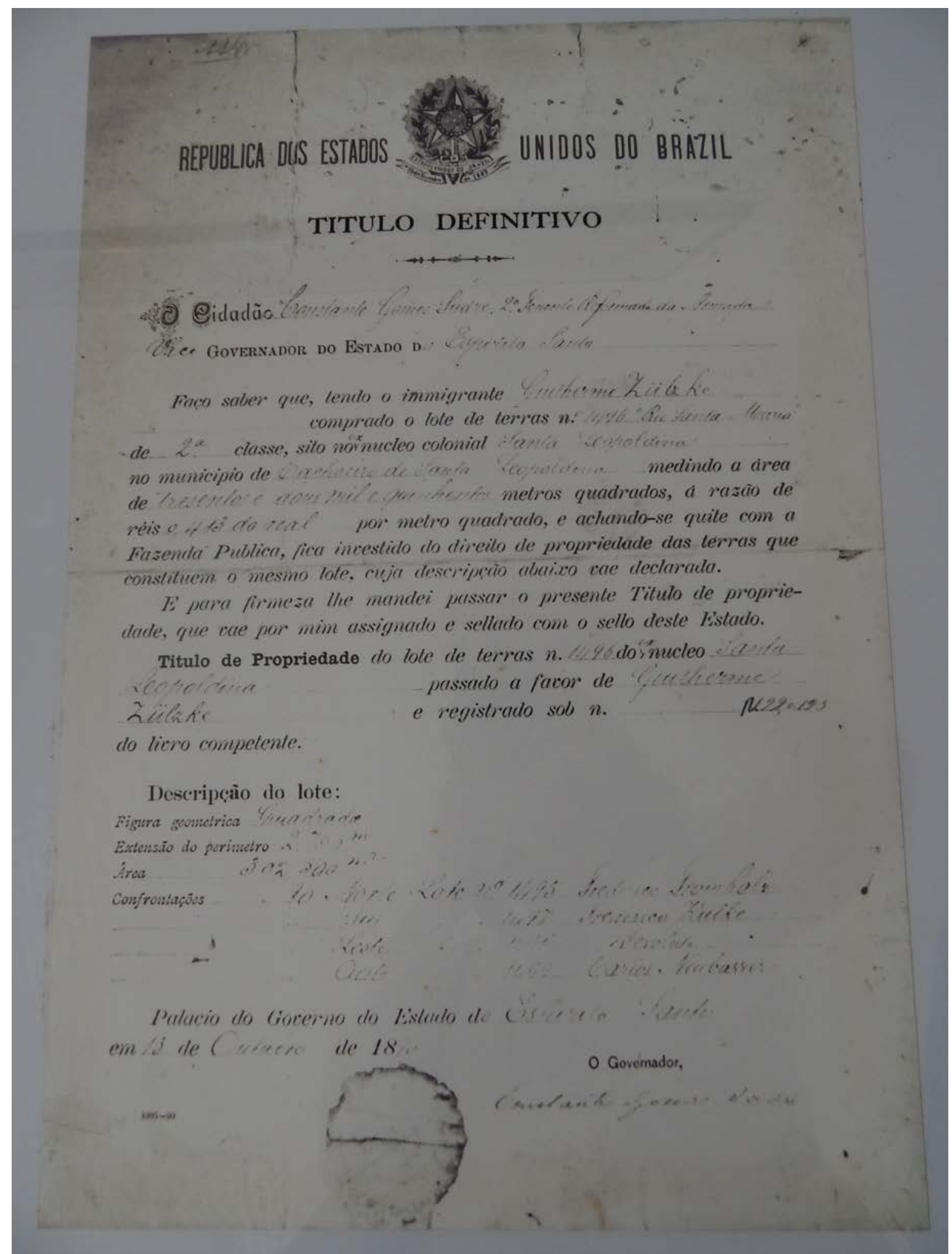

Fonte: Acervo do Museu da Imigração Pomerana de Santa Maria de Jetibá/ES 
Figura 2: Designação de lote de terras

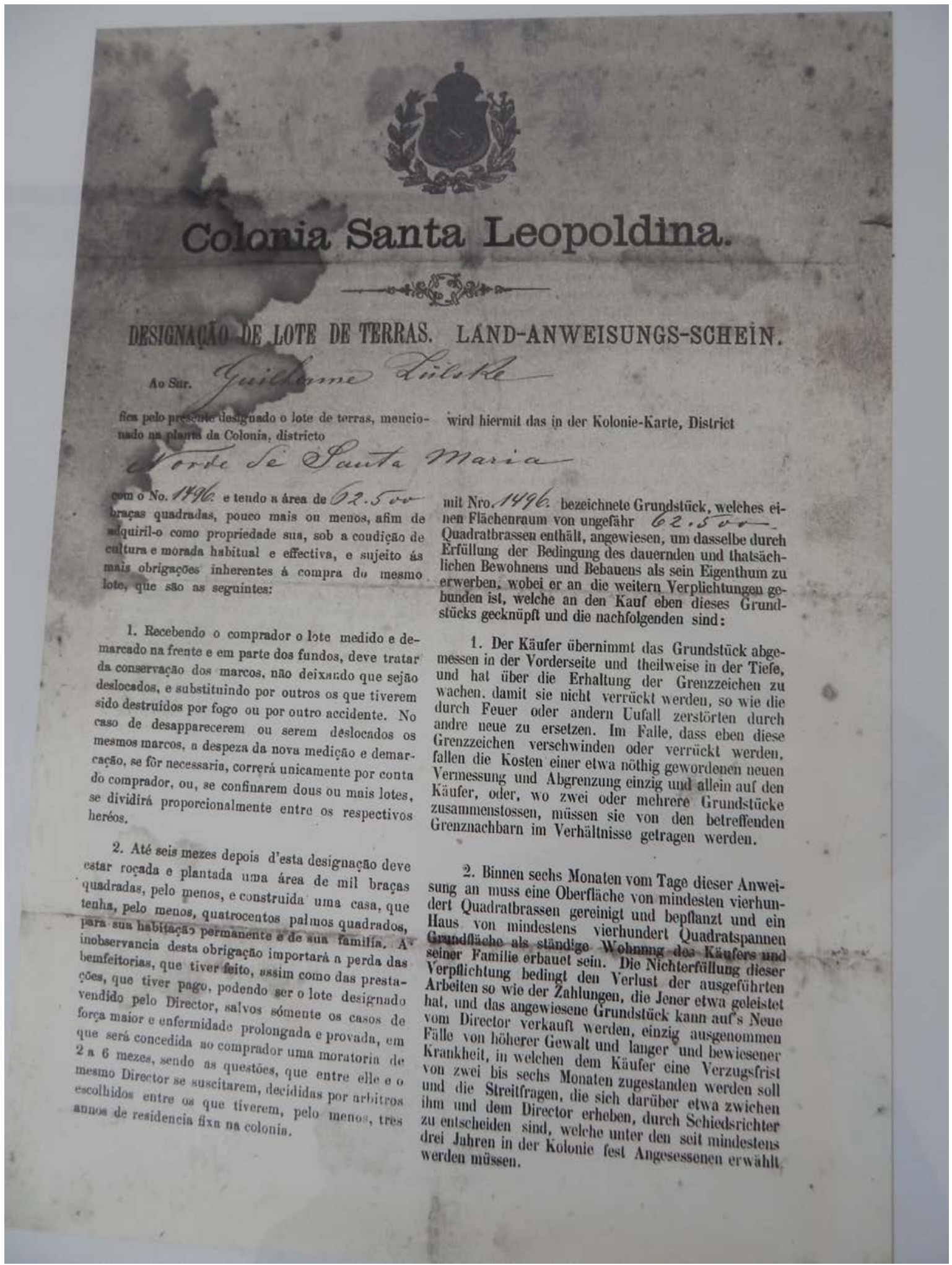

Fonte: Acervo do Museu da Imigração Pomerana de Santa Maria de Jetibá/ES

Assim, lucravam com a comercialização da madeira, com a ampliação do comércio, bem como com a especulação imobiliária dos lotes que seriam vendidos após a valorização dos terrenos, com o povoamento das 
terras e com as melhorias nos transportes e comércio da região (IOTTI, 2003, p. 10). Além disso, garantiriam que os imigrantes permanecessem fixados à terra, pois não poderiam buscar trabalho em outro local ou tentar a vida de outra forma, já que estavam obrigados ao cumprimento do contrato. A ocupação e a organização territorial dos imigrantes seguiram a lógica da possibilidade de escoamento dos produtos, em colônias instauradas ao longo de cursos de rios navegáveis (REINHEIMER, 2000, p. 26). É possível visualizar um grupo de colonos em mutirão para abertura de estradas, pela fotografia a seguir (figura 3).

\section{Figura 3: Mutirão para abertura de estradas na Colônia de Santa Leopoldina}

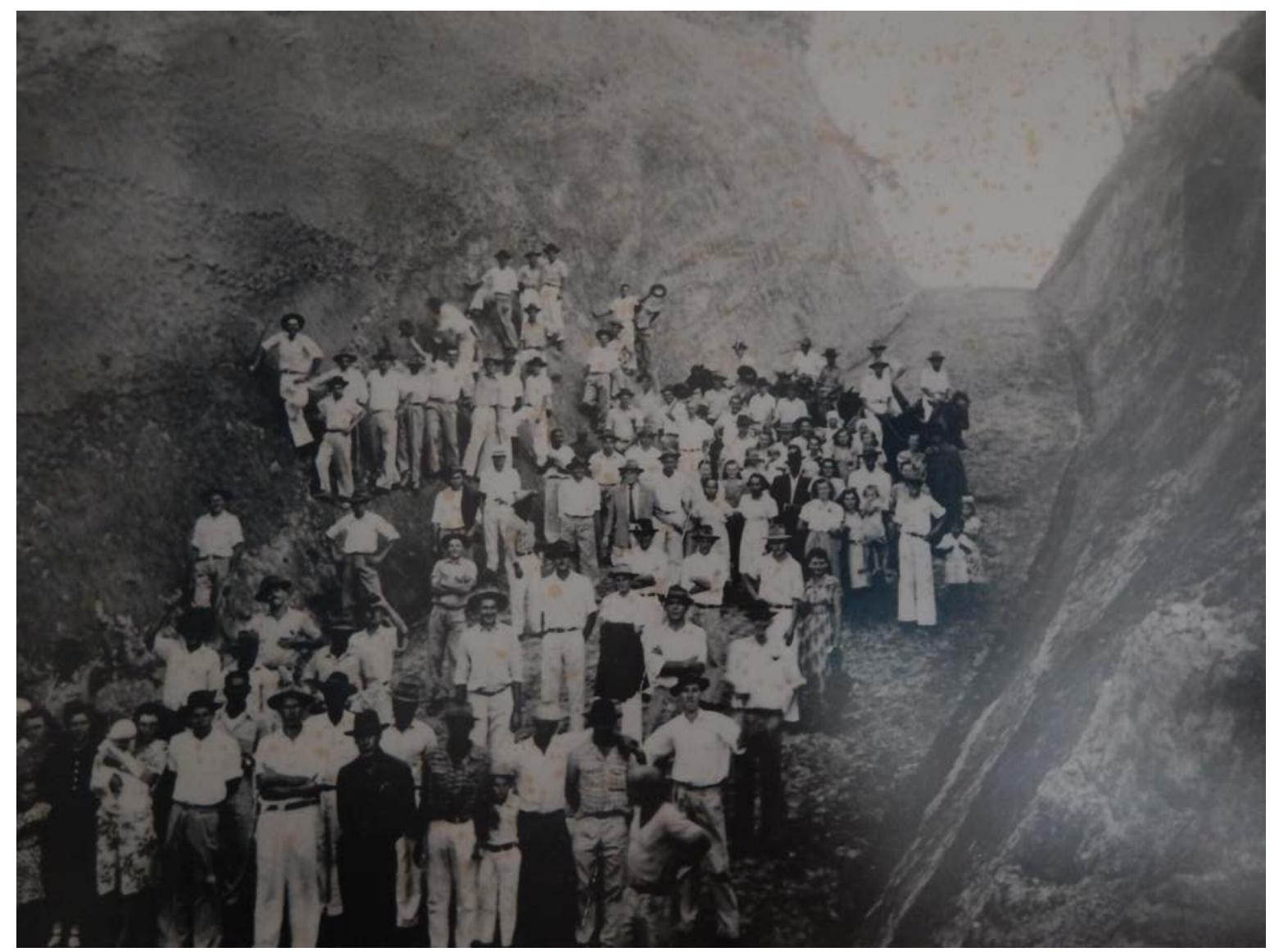

Fonte: Acervo do Museu da Imigração Pomerana de Santa Maria de Jetibá/ES

Woortmann (1995, p. 98) destaca que o processo de ocupação de terras por colonos interessava à lógica capitalista por duas razões: pela valorização das terras, ao entrar no circuito de transferência da mercadoria terra e, ao mesmo tempo, ao criar um campesinato parcelar. Para além disso, possibilitava também expropriar o posseiro e dinamizava o comércio, com a comercialização da produção. Em todas as regiões em que foram instaladas colônias, os grupos indígenas, que habitavam originariamente o território, foram expulsos ou dizimados.

Havia ainda outras questões subjacentes a essa proposta, como o branqueamento da população. Essa tese se reforça pela proibição da entrada de imigrantes chineses no período monárquico e início da República 
(ALVIM, 1999; BUENO, 2006). O advento de imigrantes, preferencialmente europeus, era considerado a solução para os problemas do atraso e da formação étnica do país. A imigração possibilitaria o processo de liberalização do mercado de trabalho, em substituição ao trabalho escravizado e, ao mesmo tempo, resolveria a questão da miscigenação, atuando no processo de embranquecimento da população (MARTíNEZ, 2003, p. 18).

O maior contingente imigratório alemão entrou no Brasil entre 1850 e o final do século XIX, o que se deduz pelo número de colônias estabelecidas nesse período. Contudo, não há estatísticas exatas do número de pessoas que imigraram da Alemanha para o Brasil. As estatísticas oficiais, cujo início data de 1884, demonstram que, entre 1884 e 1939, chegaram ao Brasil 170.645 alemães. Eduardo Prado apresenta números aproximados, anteriores as estatísticas oficiais: de 1818 a 1830, 6.856 alemães; de 1830 a 1888, 71.247 alemães. O número total de imigrantes de língua alemã que aportaram no Brasil, em cinquenta anos, de 1886 a 1936, é de 280.000 pessoas, apenas $7 \%$ do número total de imigrantes de todas as nacionalidades que o Brasil recebeu nesse período. Os colonos de origem alemã se concentraram em determinadas áreas, distantes do contato com os indivíduos lusobrasileiros. As colônias ficaram isoladas por várias décadas, antes da chegada de imigrantes de outras nacionalidades, como os italianos, a partir de 1870 (SEYFERTH, 1974, p. 33).

Segundo Franceschetto (p. 20), dos 45.630 imigrantes, das diversas nacionalidades, que chegaram ao Espírito Santo, no período de 1812 a 1900, 3.966 eram alemães e 34.516 eram de origem italiana, maioria absoluta. Foram formados, no sul do Brasil e, em menor escala, no Espírito Santo, núcleos coloniais etnicamente homogêneos. A introdução posterior de imigrantes de outras nacionalidades em áreas próximas não alterou o sistema de colonização ocorrido (SEYFERTH, p. 33). O percentual de imigrantes provenientes da Pomerânia, dentre os 4.000 imigrantes germânicos que chegaram no Espírito Santo entre 1846 e 1900, era de 56\% (SEYFERTH, p. 29).

A colônia de Santa Isabel, primeira colônia imperial no Espírito Santo, foi fundada em 1847, próximo ao Rio Jucu, com 38 famílias originárias de Hesse e Hunsrück, respectivamente, da parte central e sudoeste da Alemanha atual. Esse grupo recebeu apoio governamental em razão do pequeno número de pessoas e da proximidade com a capital. Contudo, o principal motivo do apoio logístico foi a pretensão de atrair mais imigrantes, que seriam alocados em regiões ainda não povoadas (ROCHE,1969; FEHLBERG, 2011).

A Pomerânia era uma região situada na Prússia, subdividida em Pomerânia Anterior, a Oeste, e Pomerânia Posterior, a Leste, próxima ao Mar Báltico. Ao término da Segunda Guerra Mundial, essa província passou a não mais constar no mapa da Europa, sendo dividida pelo Tratado de Potsdam entre a República Democrática Alemã, (Pomerânia Anterior) e a Polônia (Pomerânia Posterior). A maioria dos pomeranos que imigraram para o Espírito Santo são provenientes da parte anexada à Polônia, daí alguns autores afirmarem que os pomeranos não são propriamente alemães. Fixaram-se em área montanhosa, com extensões de terras altas, 
denominadas pelos imigrantes como "terra fria" (RÖELKE, 1996). Os Municípios onde os imigrantes alemães residem são as antigas colônias de Santa Isabel e de Santa Leopoldina, formadas pelos municípios de Domingos Martins, Santa Leopoldina e Santa Maria de Jetibá. Nos distritos de Alto Santa Maria e de Vinte e Cinco de Julho, no município de Santa Teresa, também há um grande percentual de descendentes de imigrantes alemães (BAHIA, 2011, p. 21). Os grupos instalados no núcleo de Santa Leopoldina acabaram por se dispersar, ao longo das montanhas, fundando algumas cidades, entre elas Santa Maria de Jetibá, localidade onde há um grande número de descendentes que preservam diversos aspectos da cultura, principalmente a língua. Ao caminhar pela cidade é bastante comum encontrarmos grupos de residentes conversando em pomerano. Na entrada da cidade a placa de boas-vindas é bilingue (figura 4).

Figura 4: Placa na entrada do centro de Santa Maria de Jetibá

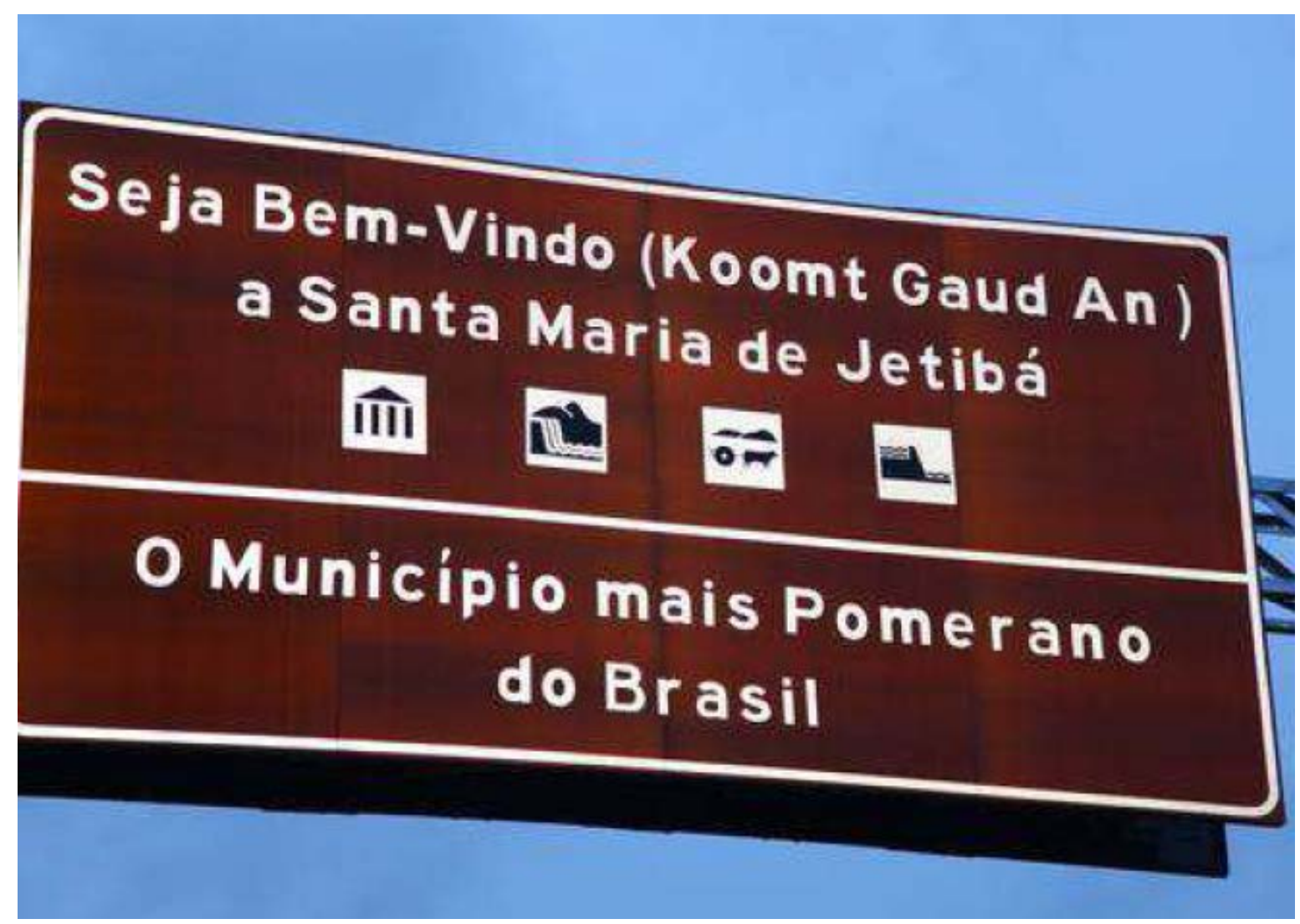

Fonte: BREMENKAMP, E.S. 2014.

A partir de 1920 inicia-se, pelos pomeranos, um período migratório em direção ao norte do Rio Doce, para as chamadas "terras quentes", localidades de Pancas, Alto Mutum Preto, Novo Brasil e Linhares (RETZ, 2005, p. 34). 


\section{O “MEDO BRANCO”: O ISOLAMENTO}

Após a chegada dos imigrantes, o "medo negro" foi substituído pelo "medo germânico" ou, germanofobia. Enquanto o "medo negro" era motivado pelo receio de um motim em larga escala, o "medo germânico" estava mais relacionado ao receio da cultura não católica, pois os imigrantes alemães eram, em sua maioria, luteranos. $\mathrm{O}$ Catolicismo era a religião oficial. Logo, certos direitos civis eram reconhecidos apenas aos católicos. Apenas os casamentos celebrados pela Igreja Católica eram reconhecidos, por exemplo, situação que persistiu até 1863, quando foi regulamentada a Lei que reconheceu os casamentos protestantes (Dreher, 1984). Fouquet (1974) assinala que o isolamento dos luteranos foi intensificado pela religião, pois a "heresia" professada em alemão pelos colonos era um fator a enfatizar o "medo germânico". As aulas e os eventos religiosos como cultos, catecismos e batizados, foram realizados em língua alemã até o período em que houve a ascensão da campanha nacionalista e o Brasil entrou na Segunda Guerra Mundial (FOUQUET, 1974; ROCHE, 1968).

O reconhecimento dos pastores protestantes como autoridades de natureza não apenas religiosa foi fator agregador que colaborou com o sentimento de pertencimento do grupo e com a coesão dos núcleos coloniais pomeranos (PEREIRA, 2001). Na fotografia seguinte o pastor luterano (figura 6) posa para fotografia com seus alunos.

\section{Figura 6: Pastor luterano e seus alunos}

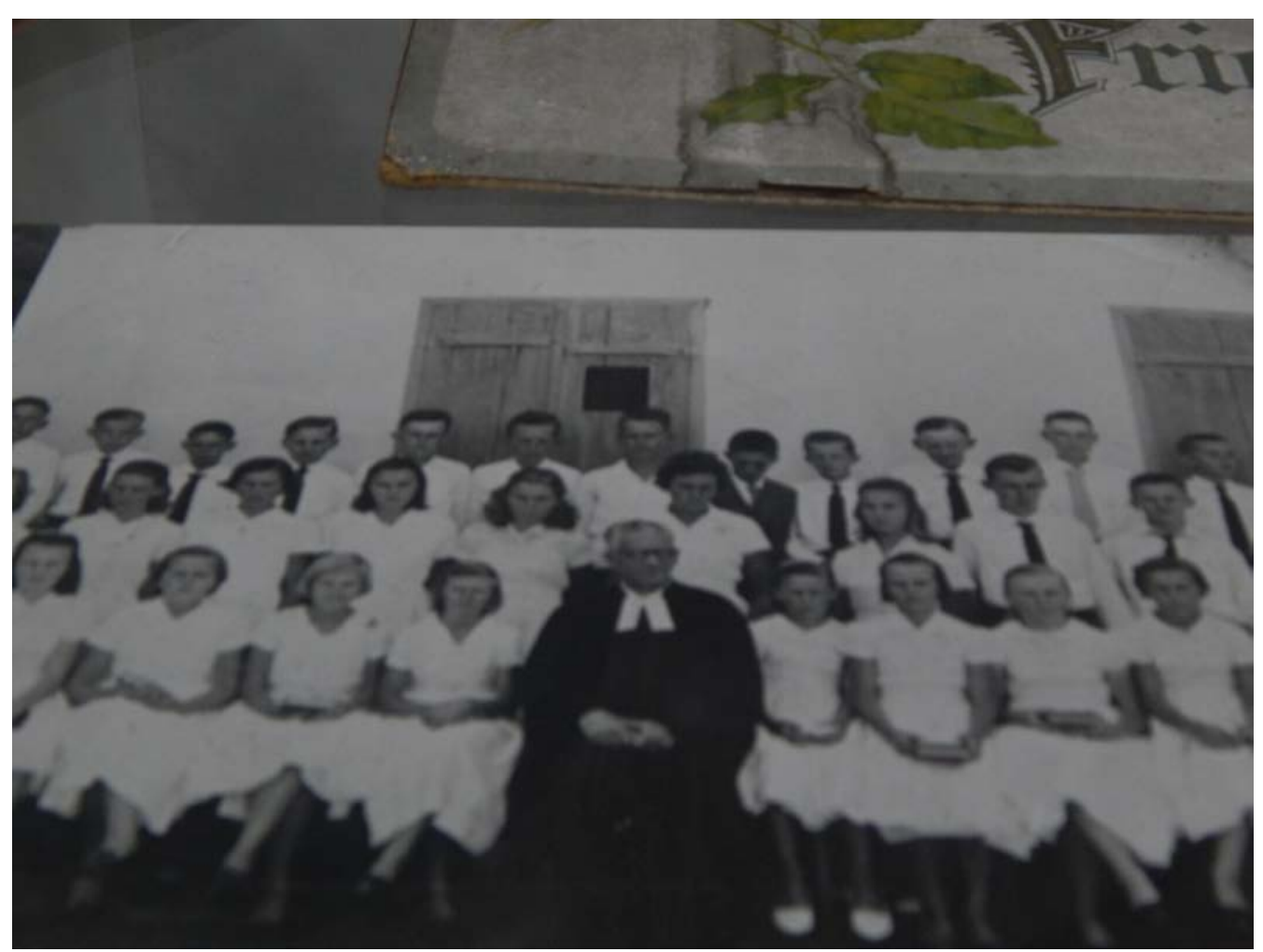

Fonte: Fonte: Acervo do Museu da Imigração Pomerana de Santa Maria de Jetibá/ES 
Em pesquisa sobre a integração de imigrantes alemães, Neumann (2000) assinala que havia engajamento de muitos descendentes e imigrantes, mesmo da primeira geração. A deflagração, no Brasil, da Campanha de Nacionalização, em 1937, pelo presidente Getúlio Vargas, contribuiu fortemente para a aceleração do processo de assimilação da língua portuguesa nas comunidades de colonização alemã. As aulas passaram a ser, obrigatoriamente, ministradas em português, sendo proibida a utilização do alemão nas escolas e nos cultos religiosos. Como os alunos não dominavam o português, anos letivos foram perdidos e o índice de evasão escolar cresceu de forma vertiginosa. $\mathrm{O}$ advento da Segunda Guerra Mundial acirrou o problema do "medo germânico": a proibição da língua alemã se estendeu a lugares públicos; publicações em jornais, documentos e livros foram apreendidos e retirados das residências e bibliotecas (ROCHE, 1969, p. 719).

Como assinala Spinassé (2008), a língua alemã continuou sendo falada nas colônias, pois muitos não falavam outra língua, principalmente os mais velhos, e esse processo acabou contribuindo para que vários elementos da língua portuguesa se misturassem ao dialeto pomerano, cada vez mais distante do alemão "correto": Hochdeutsch. O sentimento era de medo e vergonha da origem alemã. Todavia, as consequências foram mais de acirramento do isolamento do que de integração. Em verdade houve um recuo no processo de integração.

\section{A LUTA PELO (RE)CONHECIMENTO}

A região onde as comunidades pomeranas residem tem sido objeto de disputas, território de conflitos entre grupos com interesses nas riquezas do solo e, principalmente, do subsolo capixaba. A forte propensão a se instituir a identidade alemã no território do grupo reforça a tendência ao isolamento e a manutenção de sua cultura.

Uma importante conquista na temática do reconhecimento foi a inclusão das comunidades pomeranas como povo tradicional, juntamente com outros povos e comunidades. $\mathrm{O}$ ato foi realizado em 2007, com a assinatura do Decreto No 6.040, de 07 de fevereiro de 2007, pelo presidente Lula. Conforme dispõe o referido decreto, que instituiu a Política Nacional de Desenvolvimento Sustentável dos Povos e Comunidades Tradicionais, estes se caracterizam como:

grupos culturalmente diferenciados e que se reconhecem como tais, que possuem formas próprias de organização social, que ocupam e usam territórios e recursos naturais, de forma permanente ou temporária, de uso sustentável, como condição para sua reprodução cultural, social, religiosa, ancestral e econômica, utilizando conhecimentos, inovações e práticas gerados e transmitidos pela tradição, voltado para a melhoria da qualidade de vida da presente geração, garantindo as mesmas possibilidades para as gerações futuras.

Os acontecimentos que culminaram nesse reconhecimento foram relatados por Vanilda Haese Dettmann (2015), membro da Associação Pomerana de Pancas - APOP. A inclusão dos pomeranos como povo tradicional guarda relação com a criação do Parque Nacional dos Pontões Capixabas, nos municípios de Pancas e 
Águia Branca, no estado do Espírito Santo, numa área de 17.496 hectares, pelo presidente Fernando Henrique Cardoso. No processo, que culminou no Decreto, constam pareceres de ambientalistas de diversas partes do Brasil - Distrito Federal, Rio Grande do Sul, Bahia e Paraíba -, defendendo a nova área de conservação. Contudo, os moradores dos municípios envolvidos, Pancas e Águia Branca, não foram consultados e nenhuma audiência pública foi realizada, conforme ressalta Nunomura (2005).

$\mathrm{O}$ ato conflagrado de um indivíduo que detém o poder dominante, de criar uma área, supostamente de proteção, desprezando os indivíduos que residem no local, traz à luz a luta de grupos interessados, de um lado na preservação de sua identidade e, de outro, na riqueza daquelas terras ocupadas em épocas em que não eram consideradas mercadorias de valor, em uma sequência histórica, antecedente ao ato jurídico: "a história deve sempre ser escrita segundo uma norma situada fora dela" (MARX; ENGELS, 2001, p. 37).

O conflito engendrado remete "à sociedade civil em seus diferentes estágios, como sendo o fundamento de toda a história, o que significa representá-la em sua ação enquanto Estado e explicar por ela o conjunto das disposições teóricas e das formas da consciência" (MARX; ENGELS; p. 35). Tais grupos procuram apenas seu interesse particular, que nem sempre coincide com interesse coletivo, pois "a universalidade é apenas uma forma ilusória da coletividade" (MARX; ENGELS, p. 31). No embate prático desses grupos em conflito, frequentemente, nasce a necessidade da intervenção do interesse ilusório e universal que comparece sobre a forma de Estado. Esse poder social, que nada mais é que a cooperação dos diversos indivíduos, toma uma forma de algo acima do natural, estranha, fora do universo material, corpóreo, em verdade, a "materialização do poder que se constrói no jogo de interesses divergentes e forças sociais contrárias que, circunstancialmente, não se encontram apartadas territorialmente (PAULINO, 2012, p. 303). O homem passa a notar esse Estado como um domínio ao qual não tem acesso, um caminho independente da trilha do próprio homem, esquecendo-se que, na verdade, é ele quem dirige a marcha da humanidade.

A população dos municípios de Pancas e Águia Branca se organizou para reverter o quadro que se desenhava, diante da possibilidade de ter que abandonar suas casas e terras. Foi o início de um movimento contra a criação do Parque. A partir de debates com diversas organizações políticas, sindicais, civis e religiosas, foram realizadas audiências públicas com órgãos governamentais, na tentativa de garantir a permanência dos moradores dentro da área de preservação, conciliando a necessidade de se preservar um importante bioma do País, com suas diversas orquídeas, bromélias, meriânias e árvores frondosas como jequitibás, perobas-rosa, ipês e jacarandás, além da variedade de animais ${ }^{4}$. Dettmann (2015) registra a existência de interesses políticos, de grandes empreendedores, principalmente na riqueza do subsolo, motivo dos conflitos fundiários existentes no território.

\footnotetext{
${ }^{4}$ Os pontões capixabas foram considerados pelo paisagista Burle Max o lugar mais bonito do mundo, pela série de pedras de mais de 500 metros de altura torneadas pelas matas (NUNOMURA, 2005).
} 
Em 02 de junho de 2008 foi formalizada a mudança de Parque Nacional dos Pontões Capixabas para Monumento Natural dos Pontões Capixabas (Figura 7), sob a Lei no 11.686/2008, tornando-se essa, a primeira Unidade de Conservação Federal de proteção integral com permissão legal de permanência de moradores em seu interior.

\section{Figura 7: Pontões Capixabas}

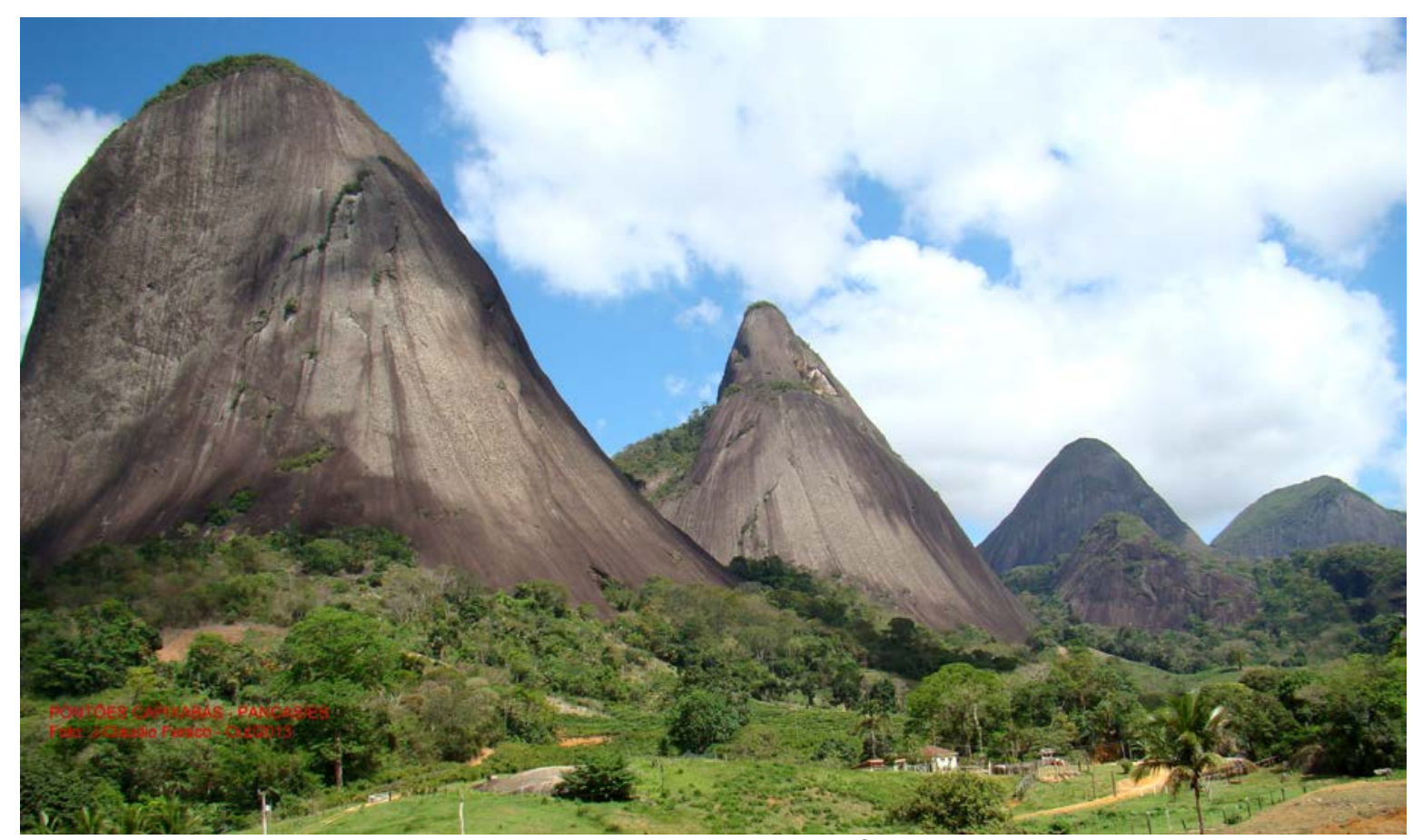

Fonte: Município de Pancas ${ }^{5}$

A objetivação e a oficialização da nomeação pública realizada, à vista de todos, subtraem a particularidade que está na origem do particularismo e tem a sua completa realização na manifestação, um ato tipicamente mágico, por meio do qual o grupo de camponeses pomeranos, até então negado, se torna manifesto, não apenas para os outros grupos, mas principalmente para si próprio, transformando o mundo social dos indivíduos (Bourdieu, 1989, p. 117-118). A identidade particular alcançada pelo simples acontecimento de assinar um decreto é legitimada, surtindo um efeito, mais que simbólico, real: a crença na unidade do Deutschtumpomerano, possibilitando que os camponeses pomeranos continuem fazendo uso dos recursos naturais, cultivando alimentos em suas terras, mantendo costumes e crenças.

\section{CONSIDERAÇÕES FINAIS}

A luta do grupo pomerano regionalista a respeito do (re)conhecimento de sua identidade étnica, a

\footnotetext{
${ }^{5} \mathrm{Http}: / /$ www.pancas.es.gov.br/Materia_especifica/6502/Principais-Pontos-Turisticos
} 
respeito de propriedades ligadas à origem comum e a signos que lhe são correlatos, como a manutenção de costumes e do dialeto pomerano, é a luta por se fazer ver, conhecer e não propriamente reconhecer. A inclusão dos grupos pomeranos como povo tradicional possibilita fazer, a unidade, realidade. Como acentua Bourdieu (1989, p. 113), a etimologia da palavra região (regio) leva a noção de re-visão, ato quase mágico, "que introduz por decreto uma descontinuidade decisória na continuidade natural", ato que consiste em "separar o interior do exterior, o reino do sagrado do reino do profano, o território nacional do território do estrangeiro". O discurso regionalista do Deutschtum é um discurso performativo que tem em vista impor, como legítima, uma nova definição das fronteiras e fazer reconhecer a cultura pomerana, seus costumes, seu modo de vida, sua relação com a terra, contra a definição dominante. $\mathrm{O}$ ato de categorização do reconhecimento de um povo e suas particularidades, ao ser exercido por uma autoridade reconhecida, exerce poder por si, transforma as categorias étnicas e instituem uma realidade (BOURDIEU, p. 116).

Como assinala Paulino (2012, p. 303), as políticas públicas e decisões políticas não são executadas "à margem dos embates teóricos". Antes, revelam lugares de classe, com consequências práticas nos movimentos de territorialização, reais, palpáveis, em um caráter contraditório de dinâmicas, as quais, por sua vez, trazem à luz a história dos sujeitos envolvidos nos embates teóricos.

A história, na verdade, significa a sucessão de diferentes gerações e cada geração explora os capitais sociais e as narrativas que a eles são transmitidas pelas gerações anteriores. A história passa ser desnaturada pela especulação. A ideia da história passada nada mais é que uma sombra, uma abstração da história anterior com objetivo de influenciar ativamente a história atual (MARX; ENGELS, p. 46-47).

Assim o isolamento primitivo do povo pomerano é destruído por um modo de produção aperfeiçoado, pela divisão do trabalho, transformando a história desse grupo em parte da história do Brasil e da história mundial, de forma que a inclusão, por decreto, das comunidades pomeranas como um povo tradicional, é mais um fato interconectado nesse universo da luta de classe, tal como o açúcar e o café tiveram sua importância no século XIX.

\section{THE HISTORICAL PROCESS OF KNOWLEDGE ABOUT THE POMERANIANS AS TRADITIONAL PEOPLE IN BRAZIL}

\section{Abstract}

This article aims to clarify some important aspects to understand the situation of isolation of pomeranians groups, an important factor in maintaining there identity of ethnic group included as traditional people in Brazil. The aim is to reconstruct the historical trajectory of these groups in order to facilitate the identification of the fight involving groups with opposing interests in the process of (re) knowledge of the identity of the Pomeranian community. The research method used is the dialectic, by contrast of conflicting ideas. The main theoretical basis of the work moves between Marxian tradition of texts. 
Keywords: Identity. Historical process. Pomeranians. Traditional people.

\section{REFERENCIAS}

ABRANTES, V. Memória sobre os meios de promover a colonização. Berlim: Typographia de Unger Irmãos: 1846. Disponível em: <http://www.brasiliana.usp.br/handle/1918/00029800\#page/1/mode/lup>. Acesso em $09 / 08 / 2016$.

ALVIM, Z. O Brasil italiano (1880-1920). In: Fazer a América. Fausto, B. (org.) São Paulo: EDUSP, 1999, p. 383417.

BAHIA, J. "A lei da vida": confirmação, evasão escolar e reinvenção da identidade entre os pomeranos. Revista Educação e Pesquisa, n.27, 2001, p. 69-82.

BIEHL, J. G. A guerra dos imigrantes: o espírito alemão e o estranho Mucker no Sul do Brasil. In: Psicanálise e Colonização: leituras do sistema social no Brasil. Porto Alegre: Artes Ofício, 1999. p. 148-168.

BOURDIEU, Pierre. O poder simbólico. Trad. Fernando Tomaz. Rio de Janeiro: Bertrand Brasil, 1989.

BRASIL. Decreto nº. 528, de 28 de junho de 1890. Regulariza o serviço da introdução e localização de imigrantes na República dos Estados Unidos do Brasil. Disponível em: <http://legis.senado.gov.br/legislacao/ListaPublicacoes.action?id=102013\&tipoDocumento=DEC\&tipoTexto $=\mathrm{PUB}>$. Acesso em 21/08/2016.

BRASIL. Decreto n. 6.455, de 19 de abril de 1907. Aprova as bases regulamentares para o serviço de povoamento do solo nacional. Disponível em: <http://www2.camara.leg.br/legin/fed/decret/1900-1909/decreto-6455-19abril-1907-502417publi cacaooriginal-1-pe.html>. Acesso em 21/08/2016.

Decreto-Lei no. 19.482, de 12 de dezembro de 1930. Limita a entrada, no território nacional, de passageiros estrangeiros de terceira classe, dispõe sobre a localização e amparo de trabalhadores nacionais. Legislação Informatizada. Disponível em: <http://www2.camara.leg.br/legin/fed/decret/1930-1939/decreto19482-12-dezembro-1930-50301 8-republicacao-82423-pe.html>. Acesso em 21/08/2016.

Constituição da República dos Estados Unidos do Brasil. Disponível em: $<$ http://www.planalto.gov.br/ccivil_03/constituicao/constitui\%C3\%A7ao34.htm>. Acesso em 23/08/2016.

Decreto-Lei no ${ }^{\circ}$ 406, de 4 de maio de 1938. Dispõe sobre a entrada de estrangeiros no território nacional. Legislação Informatizada. Disponível em: <http://www2.camara.leg.br/legin/fed/declei/1930-1939/decretolei-406-4-maio-1938- 348724-publica caooriginal-1-pe.html>. Acesso em 23/08/2016.

Decreto-Lei nº.7.967, de 18 de setembro de 1945. Dispõe sobre a Imigração e Colonização. Disponível em: <http://www.planalto.gov.br/ccivil_03/decreto-lei/1937-1946/Del7967.htm>. Acesso em 25/08/2016.

Decreto-Lei no. 4340, de 19 de dezembro de 2002. Cria o Parque Nacional dos Pontões Capixabas, nos Municípios de Pancas e Águia Branca, no Estado do Espírito Santo. Disponível em: $<$ http://www.icmbio.gov.br/portal/images/stories/imgs-unidades-coservacao/capixabas.pdf〉. Acesso em 23/10/2016.

Decreto-Lei $\mathrm{n}^{\circ}$ 6.040, de 07 de fevereiro de 2007. Institui a Política Nacional de Desenvolvimento Sustentável dos Povos e Comunidades Tradicionais. Disponível em: <http://www.planalto.gov.br/ccivil_03/_ato2007-2010/2007/decreto/d6040.htm> Acesso em 23/10/2016.

Decreto-Lei $n^{\circ} 11.686$ de 2 de junho de 2008. Altera a categoria da unidade de conservação Parque 
Nacional dos Pontões Capixabas para Monumento Natural dos Pontões Capixabas, nos Municípios de Pancas e Águia Branca, no Estado do Espírito Santo. Disponível em: <https://www.planalto.gov.br/ccivil_03/_ato20072010/2008/lei/111686.htm>. Acesso em 23/10/2016.

BREMENKAMP, E. S. Análise sociolinguística da manutenção da língua pomerana em Santa Maria de Jetibá, Espírito Santo. Dissertação de Mestrado. Programa de Pós-Graduação em Linguística do Centro de Ciências Humanas Naturais da Universidade Federal do Espírito Santo. (2014). Disponível em: $<$ https://www.google.com.br/?gws_rd=ssl\#q=placa+pomerano+santa+maria+de+jetib\%C3\%Al>. Acesso em 28 nov. 2016.

DETTMANN, V. H. Pomeranos, povo de cultura tradicional. 2015. Disponível em <https://www.kooperationbrasilien.org/de/themen/menschenrechte-gesellschaft/traditionelle-voelker-gemeinschaften/pomeranos-pocode-cultura-traticional $>$. Acesso em 21/10/2016.

DREHER, M. Há entre os pomeranos uma ética de trabalho muito acentuada. Revista do Instituto Humanista Unisinos, Edição 271.p. 1-5. 2008. Disponível em: <www.unisinos.br/ihu>. Acesso em 12/02/2016. 1995.

O fenômeno Imigratório alemão para o Brasil. In: Estudos Leopoldenses. Vol. 31, n 142, maio/junho,

FEHLBERG, J; MENANDRO, P.R.M. Terra, Família e Trabalho entre Descendentes de Pomeranos no Espírito Santo. Revista Barbarói, n ${ }^{\circ}$ 34, 201 1, p. 80-100.

Casamento pomerano e trabalho feminino: um estudo com casais de duas gerações. Pesquisas e Práticas psicossociais, no. 7(1), São João del Rei, janeiro/junho. 2011 p. 7-22.

FRANCO, M. S. C. Homens livres na ordem escravocrata. 4 ed. São Paulo: Fundação Editora da Unesp, 1997.

GUIMARÃES, A. P. VI Formação da pequena propriedade: I. Intrusos e posseiros. In.: WELCH, C. A.; MALAGODI, E.; CAVALCANTI, J. S. B.; WANDERLEY, M. N. B. (Orgs.). Quatro séculos de latifúndio. Camponeses brasileiros Leituras e interpretações clássicas volume 1. São Paulo: Editora UNESP, 2009. 335p.

IOTTI, L H. Imigração e Colonização. Revista Justiça e História, v. 3, n. 5, 2003. p. 11-42. Disponível em: <http://www.tjrs.jus.br/export/poder_judiciario/historia/memorial_do_poder_judiciario/memorial_judiciari o_gaucho/revista_justica_e_historia/issn_1676-5834/v3n5/doc/07-Luiza_Iotti.pdf $>$. Acesso em: $20 / 04 / 2016$.

MARTÍNEZ, E. G. La inmigración esperada: la política migratória brasileña desde João VI hasta Getúlio Vargas. Madrid: Consejo Superior de Investigaciones Científicas, 2003.

MARTINS, J. S. A sujeição da renda da terra ao capital. Encontros com a civilização brasileira, 22. Rio de Janeiro: Civilização Brasileira. 1980.

O cativeiro da terra. São Paulo: Hucitec, 2013.

MARX, K. O capital: crítica da economia política. São Paulo: Boitempo, 2013.

MARX, E; ENGELS F. A ideologia alemã. Martins Fontes. São Paulo: 2001.

NEUMANN, G. R. A "Muttersprache" (língua materna) na obra de Wilhelm Rotermund e Balduíno Rambo e a construção de uma identidade cultural híbrida no Brasil. Rio de Janeiro, Faculdade de Letras. (Dissertação de 
Mestrado na Universidade Federal do Rio de Janeiro). 2000.

NOVAIS, F. Portugal e Brasil na crise do antigo sistema colonial (1777-1808). São Paulo: Hucitec, 1979.

NUNOMURA, E. Quando preservar a mata atlântica se tornou caro. 2005. Disponível em: $<$ https://www2.senado.leg.br/bdsf/bitstream/handle/id/306279/complemento_1.htm?sequence=2>. Acesso em 23/10/2016.

PAULINO, E. T. Por uma geografia dos camponeses. São Paulo: UNESP, 2006.

PAULINO, E. T.; FABRINI, J. E. (Orgs.). 1. ed. Campesinato e territórios em disputa. São Paulo: Expressão Popular, 2008.

RETZ, S. Memória, vivência e testemunho. Paróquia Evangélica de Confissão Luterana em Pancas. Santa Maria de Jetibá - ES: GRAFICOL, 2005.

ROCHA, J. A colonização Alemã no Espírito Santo. São Paulo: Edusp, 1968.

SETTON, M. G. J. A teoria do habitus em Pierre Bourdieu: uma leitura contemporânea. Rev. Bras. Educ. [online]. 2002, n.20, pp. 60-70. ISSN 1413-2478. Disponível em <http://educa.fcc.org.br/pdf/rbedu/n20/n20a05.pdf>. Acesso em 07/02/2014.

SEYFERTH, G. A colonização Alemã no Vale do Itajaí-Mirim: um estudo de desenvolvimento econômico. Porto Alegre: Movimento, 1974, p. 273-311.

Nacionalismo e Identidade étnica: a ideologia germanista e o grupo étnico teuto-brasileiro numa comunidade do Vale do Itajaí. Florianópolis: Fundação Catarinense de Cultura, 1981.

A Colonização Alemã no Brasil: Etnicidade e Conflito. In: FAUSTO, Boris (org.). Fazer a América. São Paulo: EDUSP, 2000.

SPINASSÉ, K. P. Os imigrantes alemães e seus descendentes no Brasil: a língua como fator identitário e inclusivo. 2008. Disponível em: <http:/ /www.artistasgauchos.com/conexao/3/cap10.pdf>. Acesso em 25/10/2016.

VARGAS, R. P. F. SANT'ANA, A. L. O.; CASTRO, A.C. Práticas culturais pomeranas: a relação com a terra. Cadernos de Agroecologia, v. 10, n. 3, 2015.

ZALUAR, A. E. Peregrinação pela Província de São Paulo. São Paulo: Martins. [1860?]

Trabalho enviado em 19 de fevereiro de 2017.

Aceito em 29 de junho de 2017. 